This item was submitted to Loughborough's Research Repository by the author.

Items in Figshare are protected by copyright, with all rights reserved, unless otherwise indicated.

\title{
Water in oil emulsions from hydrophobized metal membranes and characterization of dynamic interfacial tension in membrane emulsification
}

PLEASE CITE THE PUBLISHED VERSION

http://dx.doi.org/10.1016/j.colsurfa.2017.06.051

PUBLISHER

(C) Elsevier

VERSION

AM (Accepted Manuscript)

\section{PUBLISHER STATEMENT}

This work is made available according to the conditions of the Creative Commons Attribution-NonCommercialNoDerivatives 4.0 International (CC BY-NC-ND 4.0) licence. Full details of this licence are available at: https://creativecommons.org/licenses/by-nc-nd/4.0/

\section{LICENCE}

CC BY-NC-ND 4.0

\section{REPOSITORY RECORD}

Silva, Pedro T. Santos, Serena Morelli, Marijana Dragosavac, Victor Starov, and Richard Holdich. 2017. "Water in Oil Emulsions from Hydrophobized Metal Membranes and Characterization of Dynamic Interfacial Tension in Membrane Emulsification". figshare. https://hdl.handle.net/2134/26028. 


\title{
Water in oil emulsions from hydrophobized metal membranes and characterization of dynamic interfacial tension in membrane emulsification
}

Pedro S. Silva ${ }^{1}$, Serena Morelli ${ }^{1}$, Marijana M. Dragosavac ${ }^{1}$, Victor M. Starov ${ }^{1}$ and Richard G. Holdich $^{1}$

${ }^{1}$ Department of Chem. Eng., Loughborough University, Leicestershire, LE11 3TU, U.K.

\begin{abstract}
Hydrophobization of metal surfaces is reported based on silanization reactions. The aim was its application to metal porous membranes for the production of water in oil emulsions using a process known as membrane emulsification. A vertical oscillating membrane system was used to carry out drop formation experiments. It is shown that drop size can be tuned between 35 and $85 \mu \mathrm{m}$ by changing just the surfactant concentration in the continuous phase. In addition, a method to determine the percentage of active pores during the membrane emulsification process is demonstrated. This method links knowledge acquired in the surfactant adsorption dynamics and drop expansion rate. Using this approach, pore velocity can be determined, which will help in determining the boundary between dripping and jetting from a pore. This study reinforces the importance of dynamic interfacial tension which must be considered in process design, and modelling purposes, particularly in two liquid phase systems using membranes such as membrane emulsification.
\end{abstract}

\section{Keywords}

Liquid drops, surfactant dynamics, membrane surface, hydrophobic, water in oil emulsion and dynamic interfacial tension 


\section{Introduction}

Emulsification using a microporous membrane to produce droplets of a desired size distribution has become an accepted technology. Most academic studies use membranes made from ceramics [1-3], silicon or glass [4, 5], surfaces that are naturally hydrophilic, but can be rendered hydrophobic by various treatments [6, 7]. However, the adoption of membrane emulsification for commercial processes has been limited, due in part to their low mechanical resistance, or pore channel structure that tends to foul with deposited material during use in long-term production [6]. The metal membranes used in this study have a welldefined pore size, a narrow pore size distribution and are equidistantly spaced. The pore channel length of these membranes is the membrane thickness which was $100 \mu \mathrm{m}$. These types of metal membranes can be made from nickel, or stainless steel, possess good chemical resistance and fulfil the mechanical resistance requirement commonly found in industry. In a former study [8], a tubular stainless steel microporous hydrophilic membrane was used in a small-scale laboratory azimuthally oscillating membrane emulsification device with throughput of $1 \mathrm{~L} \mathrm{~h}^{-1}$ (of injected phase) providing a uniform droplet size (CV $<10 \%$ ) of an oil in water emulsion. For some processes, such as controlled release particles for certain pharma application, or some analytical chromatography supports, this continuous process throughput may be equal to full-scale production. For lower value systems productivity could be raised by increasing the porosity of the tubular membrane, changing the geometry of the system, or simply injecting at a higher rate accepting a likely loss of uniformity. In the membrane manufacturing process, porosity of these membranes can be controlled and increases with bigger pore sizes and lower distances between pores. The latter should provide higher productivity, as the total number of pores present can be increased. 
However, a significant and highly practical unknown factor whenever modelling, or designing, a membrane emulsification processes is the number of 'active' pores. It is often reported that the number of pores present that participate in a membrane emulsification is very significantly less than the total number of pores present on the membrane. There is no accepted way to be able to predict the number of active pores and limited methods to estimate the value from operating data [3, 9-11].

The natural forms of stainless steel and nickel surfaces are mildly hydrophilic which is appropriate for the production of oil in water $(\mathrm{o} / \mathrm{w})$ emulsions. However, in order to produce uniform water in oil emulsions (w/o), a hydrophobic membrane is normally desired $[9,12$, 13]. To produce water in oil emulsions the surface properties of the membrane are normally changed, lowering the surface free energy and achieving a hydrophobic surface. The superficial velocity, or approach velocity of the dispersed phase liquid, during membrane emulsification can be easily determined from a knowledge of the disperse phase flow rate, and the membrane surface area. However, determining the velocity in a pore is far more complicated because many variables (porosity, wetting, dynamic interfacial tension, shear, etc.) of the system may influence this velocity. Pore velocity is an important parameter in membrane emulsification as it will determine whether working conditions are within the dripping regime (drops sheared off tangentially to the membrane surface) rather than jetting regime (drops formed by micro-jet break-up). Usually, to provide greater control over the drop size and distribution in $\mathrm{ME}$, the dripping regime is preferred: formation of drops on the membrane surface, contact angle continuous phase to solid surface $<90^{\circ}$, where drops are sheared off [14]. However, if pore velocity is increased above a certain threshold, a change occurs from the dripping to the jetting regime. In the jetting regime, a micro-jet of dispersed phase is discharged from the pore and the continuous-membrane contact angle approaches $90^{\circ}$. 
It is normally postulated that a membrane should not be wetted by the disperse phase, and ideally fully wetted by the continuous phase. Surfactants, used to stabilise the drop formed by the membrane, are complex molecules that may also act as wetting agents for the membrane and, therefore, change the surface properties of that membrane in a way that could be unwanted for the purpose of membrane emulsification. Due to their amphiphilicity, surfactants will diffuse and adsorb to interfaces where they orientate hydrophilic groups towards hydrophilic sites, while hydrophobic groups will be attracted towards hydrophobic sites. Surfactant molecules with multiple hydrophilic and hydrophobic sites can rearrange their molecule structure, influenced by concentration $[15,16]$. So, these molecules can adsorb to liquid-gas, liquid-liquid interfaces and liquid-solid interfaces. Therefore, a good knowledge of the interaction of the dissolved components that may help the disperse phase wet the membrane, and a careful control to prevent this is important. In a practical sense this may lead to a situation where the surfactant concentration should be kept low, to minimise adsorption onto the membrane, but the concentration should be sufficient to be able to stabilise the emerging drops at the desired size. Under these conditions drops emerging from the membrane may not necessarily experience the equilibrium interfacial tension of the dispersed phase-continuous phase (with surfactant) mixture, as the rate of drop growth can be greater than the rate of surfactant adsorption at the emerging interface. This has led to the term dynamic interfacial tension. Van der Graaf et. al. [17] studied in detail the influence of dynamic interfacial tension during drop formation in membrane emulsification for $\mathrm{o} / \mathrm{w}$ emulsions. It was observed that higher throughputs of the disperse phase through the membrane, or higher surfactant concentrations, led to smaller drop formation times.

From the Young equation, it follows that the wall contact angle is a function of the properties of the solid (metal membrane) and the two immiscible liquids:

$$
\cos \theta=\frac{\gamma_{C S}-\gamma_{D S}}{\gamma_{C D}}
$$


where $\gamma_{D S}$ and $\gamma_{C S}$ are the interfacial tensions of the boundary solid/disperse phase and the boundary solid/continuous phase respectively; $\gamma_{\mathrm{CD}}$ is the interfacial tension between the two immiscible liquids. A lower interfacial tension between the two fluids will, therefore, lead to a smaller wall contact angle.

Throughput of the disperse phase in membrane emulsification is key to the implementation of this process at commercial scale. The throughput is primarily dependent on the transmembrane pressure, pore size, membrane porosity and the viscosity of the fluids. The amount of active pores is also important to achieve high throughputs, as well as for design and modelling purposes. However, this is a parameter difficult to determine. There is evidence that activation of pores occurs randomly, some pores might become active while others may stop $[18,19]$. In the study reported here, it is shown that the percentage of active pores can be estimated indirectly based on the dynamic interfacial tension. A larger flow rate of dispersed phase will lead to a faster expansion rate of drop formation which will increase the dynamic interfacial tension for a given surfactant concentration. However, a larger concentration of the surfactant should reduce the dynamic interfacial tension for a given drop formation rate.

In this work, the surfactant selected to stabilize the emulsion was sorbitan monooleate (Span ${ }^{\circledR}$ 80) which is a low molecular weight surfactant, soluble in the oil phase. It was dissolved in the continuous phase and was responsible for stabilizing the aqueous polymer drops formed at the membrane surface and avoiding coalescence. The polymer dissolved in the aqueous phase was poly(vinyl alcohol). This is a surface-active polymer commonly used as the stabilizer in oil in water (o/w) emulsions [20-22]. Thus, using this formulation, there will be two surface agents adsorbing to the surface resulting in a rapid decrease of the interfacial tension while drops are being formed. Using this approach, PVA drops will be obtained and, 
if desired, they can be polymerised, forming solid particles. Production of uniform PVA particles can be very interesting when used in certain medical applications [13].

\section{Disperse phase drop size modelling}

There are several published models for the prediction of the drop size formed during membrane emulsification as a function of detachment force (shear stress), interfacial tension and pore size of the membrane. Previous work with the type of membrane used in this study was based on the following $[8,13,23,24]$ :

$$
x=\frac{\sqrt{18 \tau^{2} r_{p}^{2}+2 \sqrt{81 r_{p}^{4} \tau^{4}+4 \gamma^{2} r_{p}^{2} \tau^{2} \cos ^{2}(\theta)}}}{3 \tau}
$$

where $r_{p}$ is the pore radius, $\tau$ is the shear stress, $\gamma$ is the interfacial tension, $\theta$ is the contact angle and $x$ is the drop diameter. When applying equation (2) it is normal to consider the membrane fully wetted by the continuous phase, $\cos (\theta)=1$.

\section{Hydrophobization of metal membrane surface}

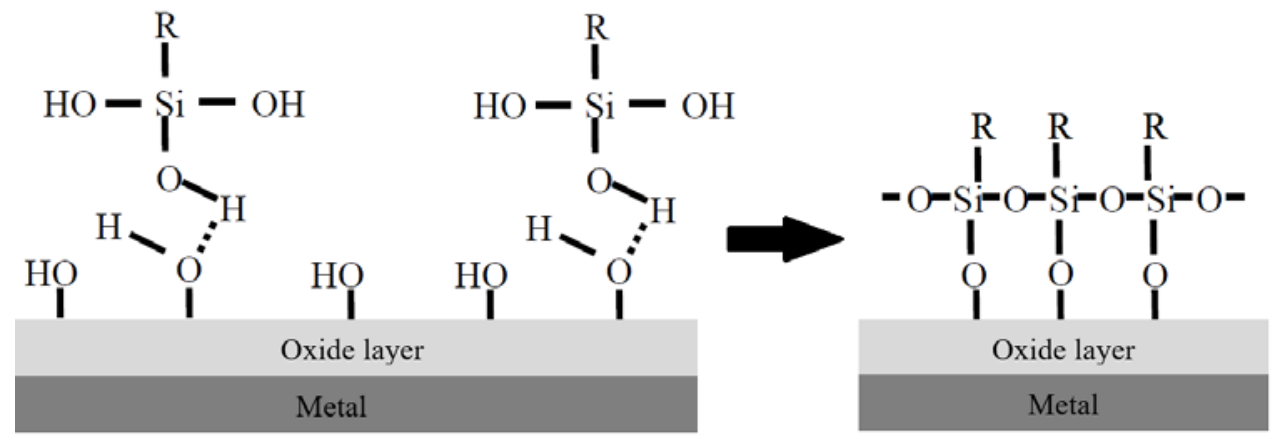

Figure 1. Representation of the ideal chemical structure of the fluoroalkylsilane/metallic interphase region $\mathrm{R}=\mathrm{CH}_{2} \mathrm{CH}_{2}\left(\mathrm{CF}_{2}\right)_{7} \mathrm{CF}_{3}$ (adapted from [25]).

Surfaces that contain available hydroxyl groups can be silanized forming a chemisorbed covalent -Si-O-Si- bond, where the hydroxyl groups attacks and replaces the alkoxy group of 
the silane [26]. Figure 1 demonstrates the process, where alkoxy group attaches to the surface hydroxyl group and, after a suitable period of time, a network of silanol groups can be chemisorbed onto the metal membrane surface, via the natural oxide coating surface on the membrane. Therefore, metals such as nickel and stainless steel can be hydrophobized by silanization reactions. Low surface free energy materials can be achieved using such a treatment employing fluoroalkylsilane (FAS), which has given rise to what is now known as super-hydrophobic surfaces [27].

Rough micro/nano structures on a hydrophobic surface provide another means to increase the dispersed phase contact angle and consequently increase its hydrophobicity (for water in oil emulsions). Roughness will increase the surface area, and air, or oil continuous phase, will be trapped between the irregularities of the surface, suspending the water drop from the hydrophobic surface such that droplet cannot adhere, but rolls off [28]. However, manufacturing such a surface adds complexity. Clearly, for commercial operation, coatings must be easy to manufacture, mechanically and chemically resistant and long-term stable. 


\section{Materials and methods}

\subsection{Emulsification}

A solution of 13.5\% wt. PVA (MW 13000 - 23000 87-89\% hydrolysed Sigma Aldrich, UK) in distilled water was used as the dispersed phase, while the continuous phase was kerosene (reagent grade, low odour, Sigma Aldrich, UK) containing an (oil soluble) surfactant - Span ${ }^{\circledR}$ 80 (Sigma Aldrich, UK) - which was used at various concentrations between 5-100 mM. A vertical oscillating membrane system was used and is illustrated in Figure 2 (supplied by Micropore Technologies Ltd.). The tubular membrane used was hydrophobized as described in section 2.2. The membrane was electroformed nickel, and had $10 \mu \mathrm{m}$ diameter pores that were spaced equidistantly $200 \mu \mathrm{m}$, in a triangular array pattern, providing a low surface porosity of $0.23 \%$. The distance between pores is 20 times higher than the pore size ensuring that contact of emerging droplets is unlikely to occur. The tubular membrane used had a working diameter of $15 \mathrm{~mm}$ and a length of $60 \mathrm{~mm}$. To reduce the turbulence resulting from oscillation, at the bottom end of the membrane, a metal cap in the shape of a cone was used, as can be observed in Figure 2, and sealed off the tubular membrane. The metal membrane had a thickness of $100 \mu \mathrm{m}$.

The membrane cleaning procedure consisted of soaking in $4 \mathrm{M} \mathrm{NaOH}$ solution for 10 minutes, followed by rinsing with tap water and then placing in distilled water for 1 minute. Afterwards, the membrane was soaked in acetone for 10 minutes to remove any organics and then dried for at least 30 minutes at room temperature. Finally, the membrane was pre-soaked in the continuous phase for at least 10 minutes, before placing it in the membrane assembly to generate a water in oil emulsion. Every time that the membrane cleaning solution was 
changed, an ultrasonic bath was used briefly to promote the cleaning and remove any air bubbles that may be trapped in the pores. After cleaning and pre-soaking in the continuous phase the membrane was mounted in the system and was driven with a sinusoidal oscillatory motion. The oscillation was parallel to the membrane tube axis. For the experiments reported below, a frequency of $35 \mathrm{~Hz}$ and peak-to-peak displacement of $2 \mathrm{~mm}$ was used. After ensuring that any air trapped in the system was completely removed, $10 \mathrm{~mL}$ of disperse phase was passed through the membrane into $200 \mathrm{~mL}$ of continuous phase containing a given concentration of surfactant $\operatorname{Span}^{\circledR} 80$, achieving a $5 \%(\mathrm{v} / \mathrm{v})$ concentration emulsion in all experiments reported.

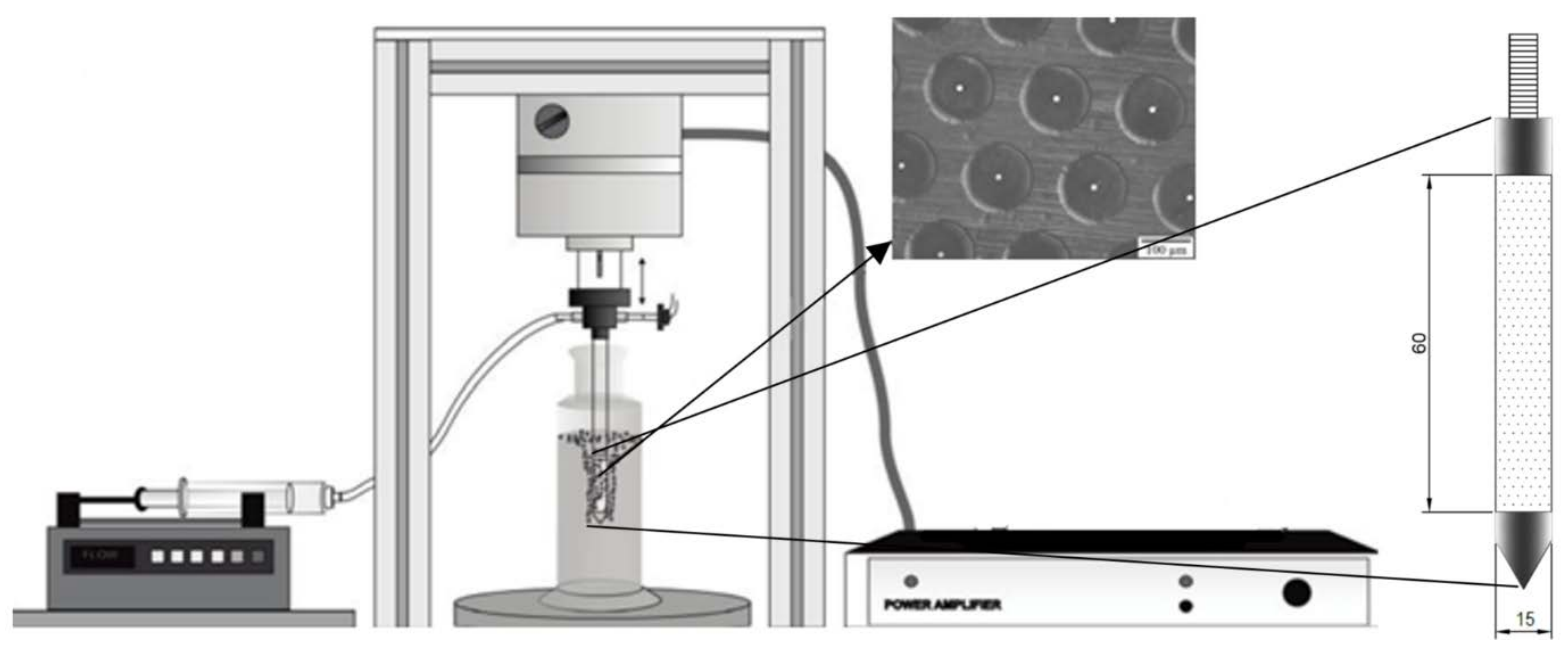

Figure 2. Representation of the vertical oscillating membrane emulsification device used with an inset showing the regular pore pattern of the membrane (triangular array) and the shape of the tubular membrane used. Adapted from [24].

\subsection{Surface modification}

Separate hydrophobization of metal surfaces tests were performed based on silanization reactions. The hydrophobic surface treatment of metal substrates made out of 316 stainless steel $(0.1 \times 25 \times 25 \mathrm{~mm}$, purchased from GoodFellow Ltd) is described in this section. Various 
parameters were experimented and explored, with evaluation of the contact angle, such as: temperature of the reaction, exposure of a metal sheet in $\mathrm{HCl}$ solution, type of silane chemical, concentration of the silane chemical, solvents, reaction time, multiple appliances of the silane chemical, etc. These will be discussed in detail in the results section. After extensive experimental tests, the procedure below is the ultimate one used to provide hydrophobic behaviour on both metal bodies: stainless steel and electroformed nickel.

\subsubsection{Developed procedure}

Firstly, the substrates were cleaned by soaking in $4 \mathrm{M} \mathrm{NaOH}$ solution for 10 minutes, followed by rinsing with tap water and then placing in distilled water for 1 minute. Afterwards, the membrane was soaked in $10 \%$ wt. $\mathrm{HCl}$ solution for 10 minutes, rinsed with tap water, and again placed into distilled water for 1 minute. The substrates were then dried at $50^{\circ} \mathrm{C}$ for 1 hour. For hydrophobization the substrates were placed in a solution of $0.01 \mathrm{M}$ 1H,1H,2H,2H-Perfluorododecyltriethosysilane which was dissolved in undecane (aprotic solvent). It was empirically found that the metal sheet should be allowed to soak in the solution for a minimum of 4 hours at $45^{\circ} \mathrm{C}$ to achieve a desirable hydrophobicity. The same procedure was applied to treat the tubular membrane which was then rinsed with acetone, dried and ready to be used in the experiments. The FluoroAlkySilane (FAS) chemical $\left(1 \mathrm{H}, 1 \mathrm{H}, 2 \mathrm{H}, 2 \mathrm{H}-\right.$ Perfluorododecyltriethosysilane) was purchased in Fluorochem $^{\circledR}$ while undecane was obtained from Sigma Aldrich, UK. 


\subsubsection{Durability and stability tests}

Five metal sheets (hydrophobic) with a known contact angle were placed in the standard solutions used to clean the metal porous membranes: distilled water, $4 \mathrm{M} \mathrm{NaOH}$ and $2 \%$ wt. citric acid for 24 hours. After this period, all the metal sheets were rinsed with distilled water and dried at $50^{\circ} \mathrm{C}$ for 1 hour. Then, contact angle measurements (sessile droplets experiments) were carried out in order to check if the hydrophobic treatment remained stable after being in contact for long a period (24 hours) with the standard membrane cleaning solutions.

\subsection{Sessile droplet experiments}

Static (apparent) contact angle measurements were obtained from sessile droplets with a home-made setup represented in Figure 3. The substrate used was a 316 stainless steel (SS) sheet $(0.1 \times 25 \times 25 \mathrm{~mm})$ purchased from GoodFellow Ltd. The substrates were chemically hydrophobically coated (see section 2.2). A DMK 23G 445 GigE monochrome industrial camera (Imaging source, Germany), coupled with Bi-telecentric lenses (OPTO Engineering, Italy), was used for monitoring the side view of the droplet. On the opposite side a light source was mounted parallel to the camera - telecentric HP Illuminator (OPTO Engineering, Italy) as shown schematically in Figure 3. Thereby a light source is positioned behind the drop, so that it appears dark.

The experimental protocol was as follows: a water droplet was deposited on the hydrophobic SS sheet which was surrounded by the organic phase (kerosene). The volume used of organic phase was about $20 \mathrm{~mL}$, contained in a (optical) glass chamber of 40x40x30 mm. During experiments the chamber was covered in order to avoid dust deposition. The cleaning of the substrate consisted of placing the SS sheets in acetone followed by drying at $50^{\circ} \mathrm{C}$ for at least 
30 minutes before the start of a new experiment. The drop deposition was performed using a micro-syringe (500 $\mu \mathrm{L})$ mounted in a support designed to improve the drop placement accuracy. Drop deposition on substrates that were surrounded by kerosene was also performed. These measurements were performed in triplicate.

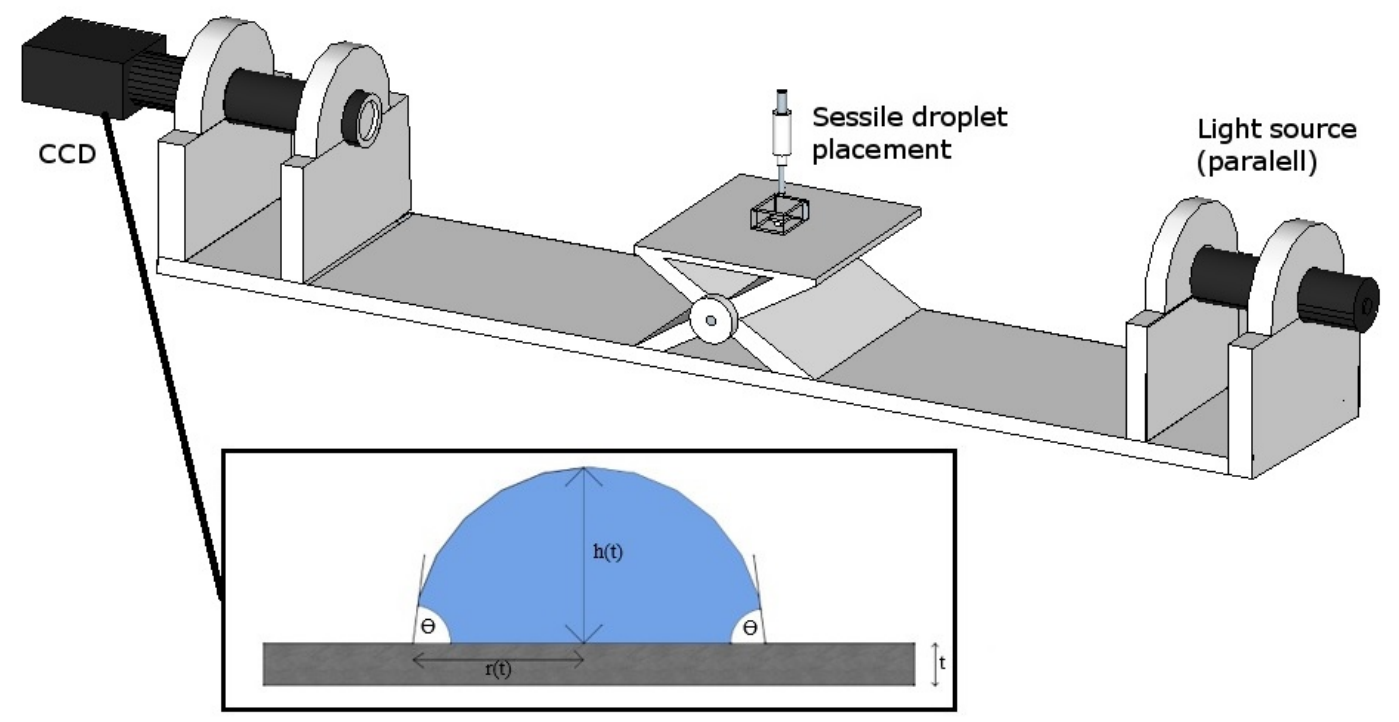

Figure 3. Illustration of the home-made sessile droplet experimental equipment.

Image analysis was undertaken using a feature called Vision Builder from LabView (National Instruments). A script was programmed to acquire the following measurements of the droplet: height (h), contact angle $(\Theta)$ and radius (r) of the droplet base. Therefore, the volume of the droplet could also be calculated.

\subsection{Interfacial tension measurements}

Dynamic interfacial tension was measured with a Drop Shape Analyser (DSA-100, Kruss, Germany) by drop shape analysis using the pendant drop method. These experiments were performed at room temperature $\left(22 \pm 2^{\circ} \mathrm{C}\right)$. The same solutions, that were used in the emulsification, were used in the interfacial tension measurements: for the droplet phase, 
distilled water and 13.5\% (w/w) PVA solution was used while the surrounding (i.e. continuous) phase was kerosene with various concentrations of $\operatorname{Span}^{\circledR} 80$. As soon as a drop was created snapshots were taken every 0.5 seconds and the drop shape was evaluated with respect to time [29]. The experiment was deemed to have finished when the interfacial tension measurements achieved an equilibrium value. These measurements were performed in triplicate.

\subsection{Determination of mean droplet size and droplet size distribution}

The droplet diameter is expressed as the volume median diameter $\mathrm{D}(\mathrm{V}, 0.5)$, which is the diameter corresponding to $50 \%$ on the cumulative volume distribution curve. Droplet size uniformity is expressed in terms of coefficient of variation (CV):

$$
C V=\frac{\sigma}{\mu} \times 100
$$

where $\sigma$ is the standard deviation and $\mu$ is the mean of the volume distribution curve. The CV and $\mathrm{D}(\mathrm{V}, 0.5)$ reported were obtained by static image analysis where a large number of (typically over a thousand) drops were counted and measured using the microscope and Image $\mathrm{J}$ (image processing software) in a process automated by running a MATLAB ${ }^{\circledR}$ script. 


\section{Results and Discussion}

\subsection{Surface modification}

As can be seen in Figure 4, regardless of the pre-treatment/cleaning of the metal sheet the apparent contact angle increases over the drying period (at $45^{\circ} \mathrm{C}$ ) for about $1-2$ hours from 30 $\pm 5^{\circ}$ to $85 \pm 5^{\circ}$. Therefore, for this type of substrate (metal, susceptible to oxidation when exposed to air) the reported contact angle will depend on how it has been handled as well as its storage conditions.

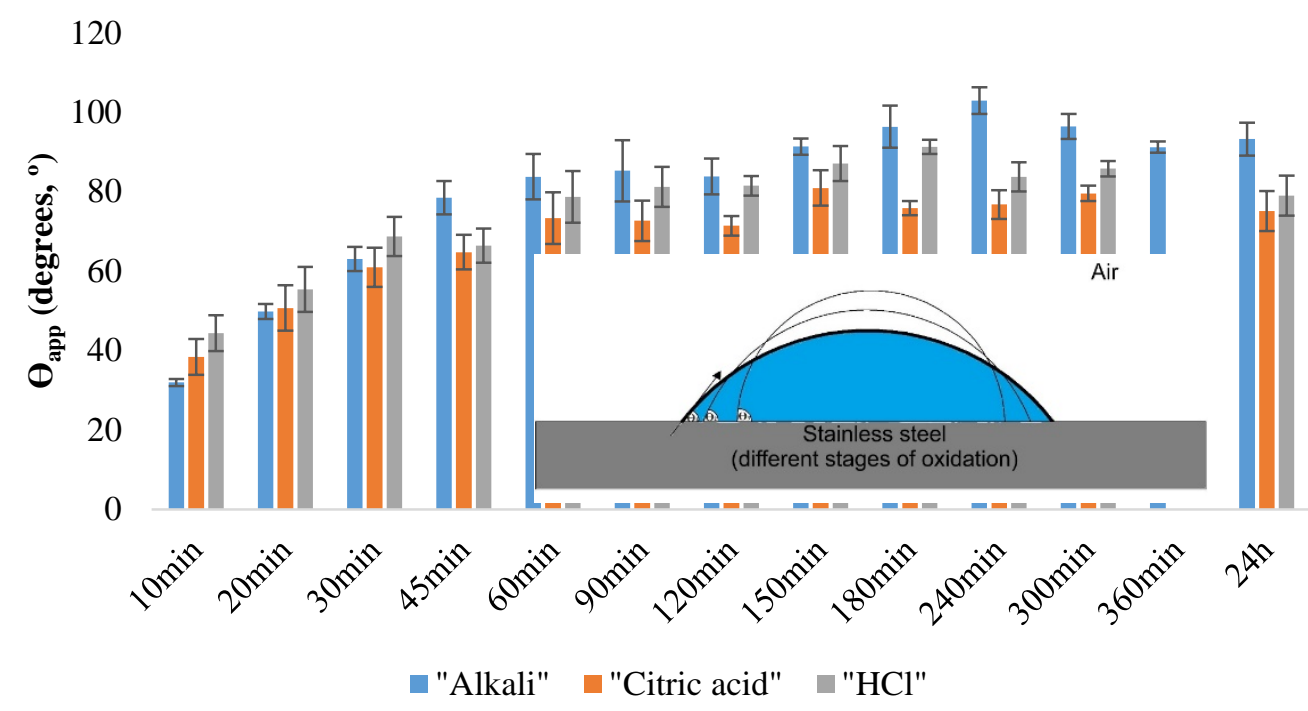

Figure 4. Apparent contact angle $\left(\Theta_{\text {app }}\right)$ monitoring of sessile water drops on stainless steel sheets that were exposed to $4 \mathrm{M} \mathrm{NaOH}$ (“alkali”), $2 \%$ (wt) citric acid or $10 \%$ (w/w) $\mathrm{HCl}$ over a variable drying period.

It is apparent from Figure 4 that the contact angle, and therefore degree of surface oxidation, remains roughly constant after about one hour. Thus, in order to provide a consistent surface for the silanization stage, see Figure 1, a procedure of leaving the metal for a minimum of one hour after cleaning before treating with FAS solution was adopted. 
Initial experiments indicated that minimum soaking time required to achieve a contact angle around $110^{\circ} \mathrm{C}$ at room temperature using a concentration of $0.01 \mathrm{M} 1 \mathrm{H}, 1 \mathrm{H}, 2 \mathrm{H}, 2 \mathrm{H}-$ Perfluorododecyltriethosysilane. Therefore, a series of experiments were designed in order to optimise the process by possibly enhancing the contact angle.

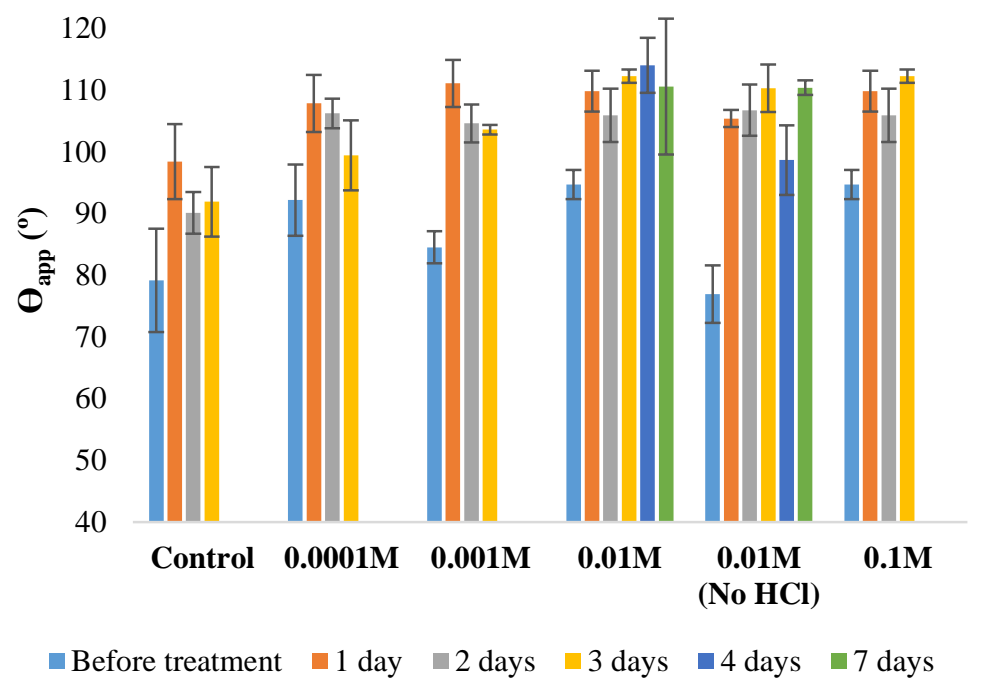

Figure 5. Apparent contact angle $\left(\Theta_{\text {app }}\right)$ measurements of sessile water drops on stainless steel sheets that were "FAS treated" using different concentrations of $1 \mathrm{H}, 1 \mathrm{H}, 2 \mathrm{H}, 2 \mathrm{H}-$ Perfluorododecyltriethosysilane $(0.0001 \mathrm{M}, 0.001 \mathrm{M}, 0.01 \mathrm{M}$ and $0.1 \mathrm{M})$ in undecane for various periods of time (1-7 days) at room temperature. As control, the presence of FAS chemical was avoided, exposing the surface only to undecane. The stainless steel used in the set named “0.01M No HCL” was not cleaned using $\mathrm{HCl}$, all the others were.

Contact angles reported in Figure 5 were obtained from a series of experiments where a metal (stainless steel) sheet was treated in order to obtain a hydrophobic metal surface. A FAS chemical $(1 \mathrm{H}, 1 \mathrm{H}, 2 \mathrm{H}, 2 \mathrm{H}-\mathrm{Perfluorododecyltriethosysilane)} \mathrm{was} \mathrm{used} \mathrm{and} \mathrm{bonded} \mathrm{to} \mathrm{the}$ surface through the silanization reaction (see section 1) lowering the surface free energy. Overall, the maximum contact angle achieved is about $110^{\circ} \mathrm{C}$. Apparently, a (minimum) concentration of $0.01 \mathrm{M}$ is suitable to achieve that level of hydrophobicity within 1-3 days. The need of exposing the metal surface to cleaning using $\mathrm{HCl}$ is not conclusive based on the contact angle evaluation. However, the metal (nickel) porous membrane treated to perform 
the drop formation experiments was exposed to $\mathrm{HCl}$ following the procedure described in section 2.2.1. The reason for exposing the metal body to $\mathrm{HCl}$ is to remove any impurities that may be absorbed to the surface, in a process known as pickling.

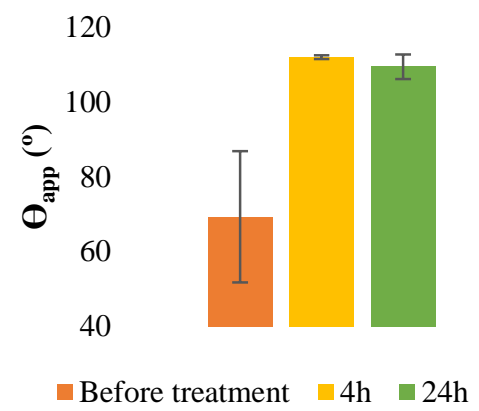

Figure 6. Apparent contact angle $\left(\Theta_{\mathrm{app}}\right)$ measurements of sessile water drops on stainless steel sheets that were "FAS treated" using a concentration of $0.01 \mathrm{M}$ of $1 \mathrm{H}, 1 \mathrm{H}, 2 \mathrm{H}, 2 \mathrm{H}$ Perfluorododecyltriethosysilane in undecane for 4 hours and 24 hours at $45^{\circ} \mathrm{C}$.

As can be seen in Figure 6, silanization reaction time can be reduced to 4 hours at $45^{\circ} \mathrm{C}$, achieving a contact angle of about $110^{\circ} \mathrm{C}$ which is equivalent to the maximum contact angles observed in Figure 5.

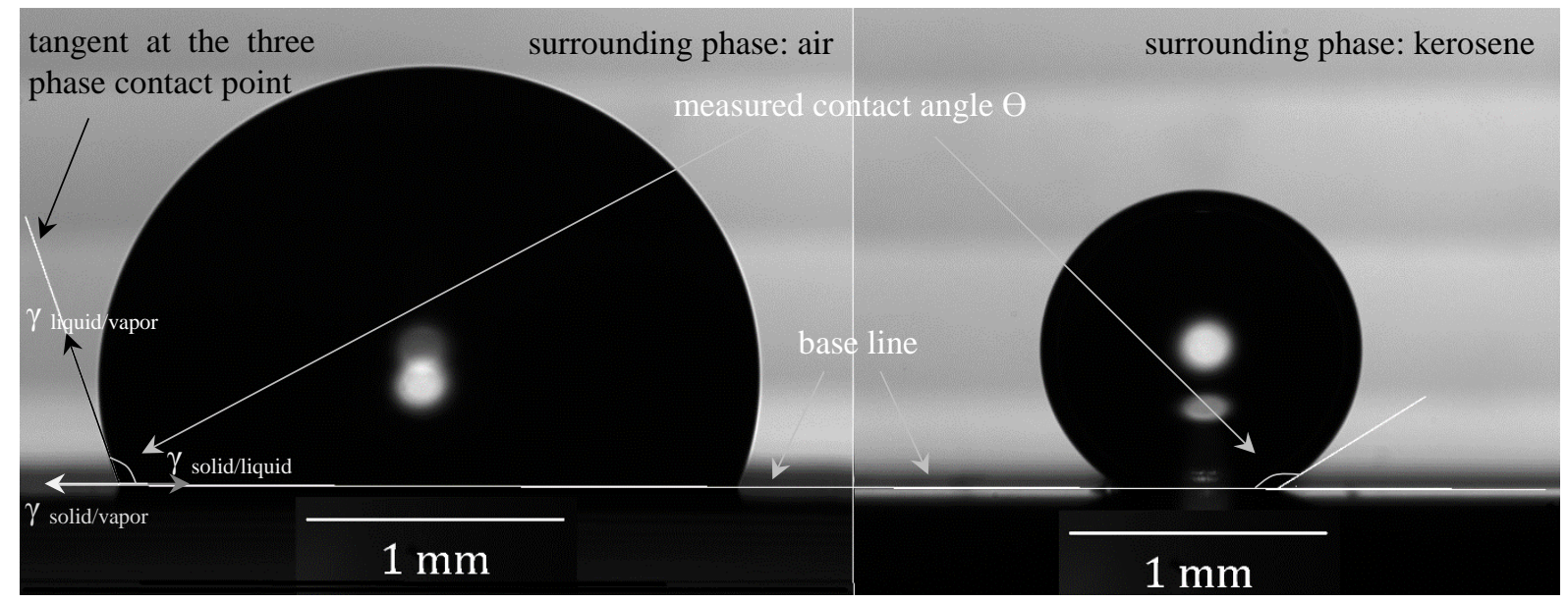

Figure 7. Image of a sessile water drop on a hydrophobic stainless steel (FAS treated) surface: (a) in air and (b) in kerosene, illustrating the interfacial tensions involved. 
In Figure 7, there are two images of a water droplet sitting on a FAS treated metal sheet surrounded by air (a), $\Theta_{\text {app }}=110 \pm 8^{\circ}$, and by kerosene (b), $\Theta_{\text {app }}=150 \pm 5^{\circ}$. This increase in the $\Theta_{\text {app }}$ was expected according to the Young equation (equation 1), i.e. the lower interfacial tension between drop phase and surrounding phase will lead to a higher contact angle. The contact angle achieved in air, $110 \pm 8^{\circ}$, is very similar to the reported contact angle for polytetrafluoroethylene (PTFE) [30-32], which is a material commonly used for hydrophobic applications. In ME apart from the degree of hydrophobicity, it is important to achieve a surface that will maintain its characteristics over the emulsification period, to avoid any change of the contact angle and therefore change of the resultant droplet size, widening the drop size distribution [33].

The developed treatment was simple to apply and, in principle, could be easily applied at bigger scales to hydrophobize a metal membrane for the purpose of membrane emulsification to produce water-in-oil emulsions. It is also simple to reapply the FAS treatment to a surface. The stability of the surface treatment was evaluated by exposing the metal sheets hydrophobically treated for 24 hours to the standard membrane cleaning solutions. Contact angle measurements indicate that hydrophobicity is kept after being exposed to water and a strong alkali $(4 \mathrm{M} \mathrm{NaOH})$ solution, but is reduced when is exposed to citric acid. Therefore, a hydrophobically treated membrane should not be cleaned with reducing agents such as citric acid, otherwise it must be recoated (further details of this contact angles measurements can be found in supplementary material).

In previous work by S. Morelli et. al. [34], two types of hydrophobic nickel membranes were used: PTFE coated (supplied by Micropore Technologies Ltd.) and FAS treated (with the optimised process that is described in this work). Uniform w/o emulsions were produced using both membranes, however further details, disclosed here, show that FAS treatment is an effective and reliable method for producing multiple uniform w/o emulsions. In Figure 8, 
water based droplets are shown with a formulation reported previously [34], in order to evaluate the performance of a PTFE coated and a FAS treated membrane for multiple emulsions. Operating parameters and cleaning cycles between the runs were equal in order to allow a direct comparison. Figure 8 shows the pictures of emulsions obtained using a new PTFE or FAS coated membrane (Fig. 8 a- PTFE and c- FAS) and PTFE or FAS coated membranes (Fig. 8 b- PTFE and d- FAS) after they have been used 4 times.

From Figure 8 a- PTFE it is visible that the emulsion obtained with the new PTFE coated membrane was uniform $(\mathrm{CV}=18 \%)$ while a reduction of the uniformity is visible after multiple uses: the fourth emulsion produced using the same membrane had a $\mathrm{CV} \%=35 \%$ (Figure 8 b- PTFE). Uniform drops were produced with a new FAS coated membrane with a measured CV\% of 22\% (Figure 8 c- FAS), and a CV of 24\% was measured for the fourth emulsion produced using the same FAS coated membrane (Figure 8 d- FAS). It is noticeable that a new PTFE coated membrane gives smaller droplets than a new FAS coated membrane. In fact, this is an indication that the new PTFE membrane presented a higher level of hydrophobicity than the new FAS. However, after multiples uses, the PTFE coating is rendered less effective, producing larger droplets and resulting in a wider size drop distribution. Thus, FAS treated membranes are shown to be more stable, durable and reliable for producing multiple emulsions. 

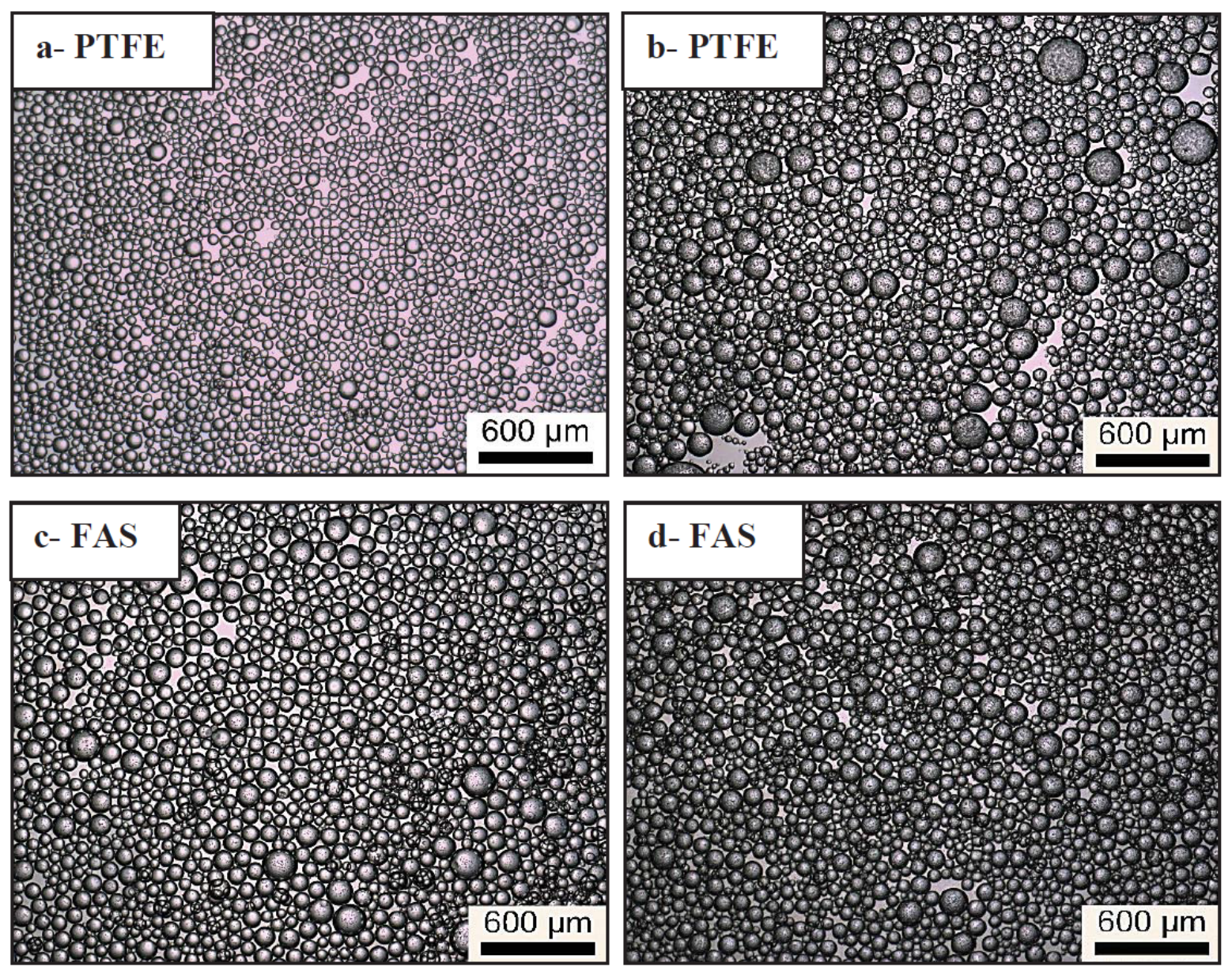

Figure 8. w/o emulsions produced using (a-PTFE) a new PTFE coated membrane, (b-PTFE) PTFE coated membrane after 4 uses, (c- FAS) a new FAS treated membrane and (d- FAS) a FAS treated membranes after 4 uses.

\subsection{Droplet formation experiments}

It can be seen in Figure 9 that droplet size decreased with surfactant concentration. Higher surfactant concentrations led to faster adsorption of surfactant on the emerging drop new interfaces, speeding the surface coverage and decreasing the time needed to achieve an equilibrium interfacial tension. In these experiments, oscillation conditions were kept at 35 $\mathrm{Hz}$ and $2 \mathrm{~mm}$ peak-to-peak, resulting in a maximum peak shear event value of 7.3 Pa, and employing a constant disperse phase flow of $1 \mathrm{~mL} \mathrm{~min}^{-1}$. Therefore, in these tests the only 
variable was the amount of surfactant available to cover newly formed interface formed by the drop as it emerged from the metal membrane pore.

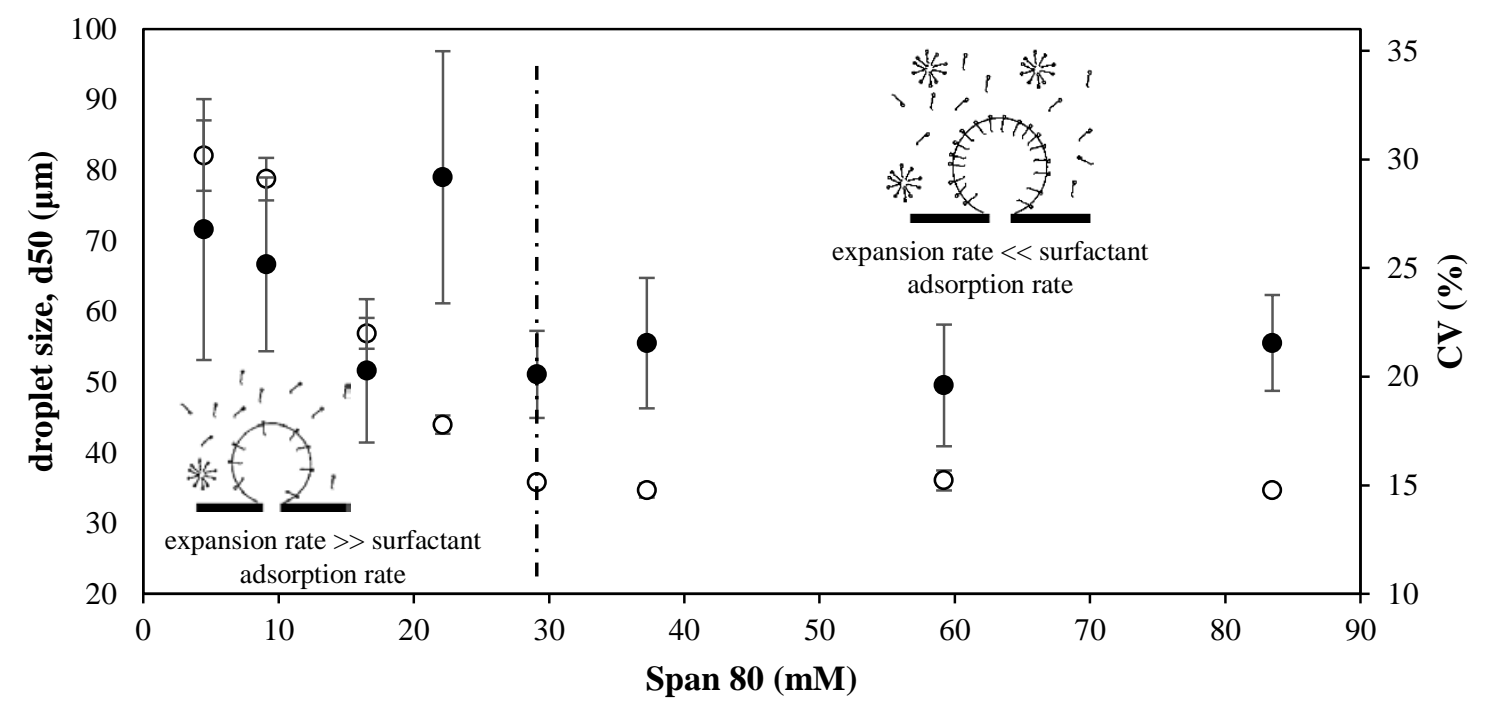

Figure 9. Median droplet diameters $(\bullet)$ and coefficient variation $(\mathrm{CV})$ values $(\bigcirc)$ of PVA droplets in kerosene as a function of concentration of $\operatorname{Span}^{\circledR} 80$ for a (constant) flow of $1 \mathrm{~mL}$ $\min ^{-1}$ during membrane emulsification of a FAS treated metal (nickel) membrane. Error bars are reported showing the standard deviation of the measurements.

A typical example of the resulting emulsion, and a drop size distribution, is illustrated in Figure 10.
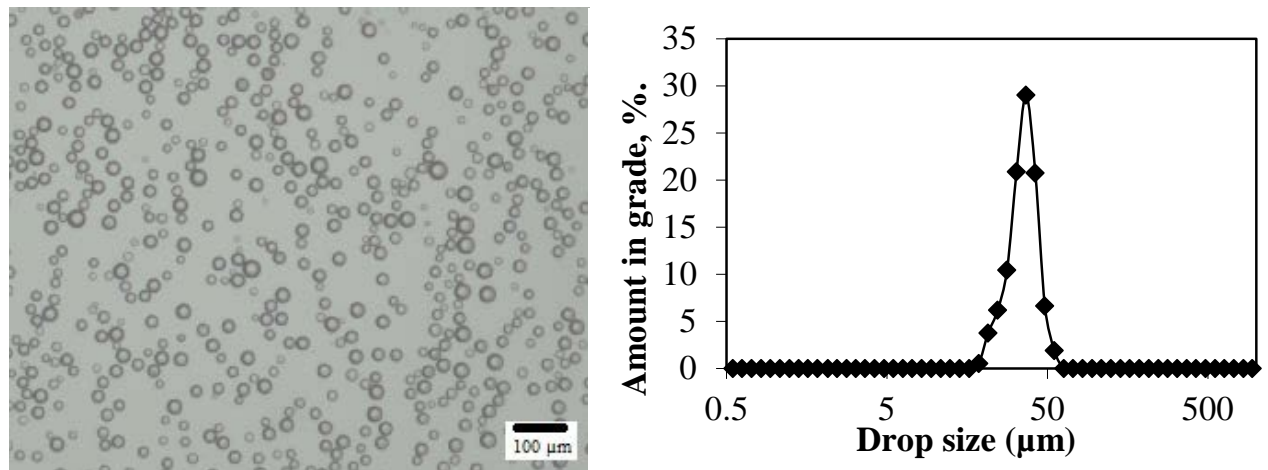

Figure 10. Droplets formed during injection of $13.5 \%$ PVA solution at $1 \mathrm{~mL} \mathrm{~min}^{-1}$ in to kerosene with $40 \mathrm{mM} \operatorname{Span}^{\circledR} 80$ surfactant concentration using a surface shear of 7.3 Pa. 
These tests were batch experiments and available surfactant concentration to stabilise freshly emerging drops will decrease with time during the experiment, as new interfaces will be created throughout. Any effect of this will be more noticeable for the lowest concentration of surfactant tested, as there is a lower amount of surfactant available at the beginning of the experiment. At high surfactant concentrations, surfactant depletion will not be significant. This phenomenon helps to explain the improving CV with respect to surfactant concentration. Rearranging the force balance model, equation (2), it is possible to estimate the dynamic interfacial tension of the drops when they are released from the membrane. The rearranged equation (2), with substitution of the constant conditions used in the experiments and assuming that the continuous phase fully wets the membrane, is shown in equation (4):

$$
\gamma=\frac{4.5 \tau x \sqrt{\left(\frac{x}{2}\right)^{2}-r_{p}^{2}}}{r_{p}}
$$

Figure 11 illustrates the interfacial tension determined by equation (4) as a function of surfactant concentration. The equilibrium value of interfacial tension, for concentrations of surfactant above the Critical Micelle Concentration (CMC) is $3 \pm 0.8 \mathrm{mN} \mathrm{m}^{-1}$. Thus, for surfactant concentrations below $29 \mathrm{mM}$ it appears that the deduced interfacial tension lies between the water-kerosene interfacial tension of $38 \pm 1.9 \mathrm{mN} \mathrm{m}^{-1}$, and the equilibrium value of interfacial tension. The value of $38 \pm 1.9 \mathrm{mN} \mathrm{m}^{-1}$ represents the maximum value of interfacial tension, when there is no presence of surface active agents at the interface as PVA or Span ${ }^{\circledR}$ 80. Hence, these deduced values are dynamic interfacial tension values, as the rate of drop growth is greater than the rate of surfactant arrival at the interface needed to stabilise the drop at the equilibrium interfacial tension value. 


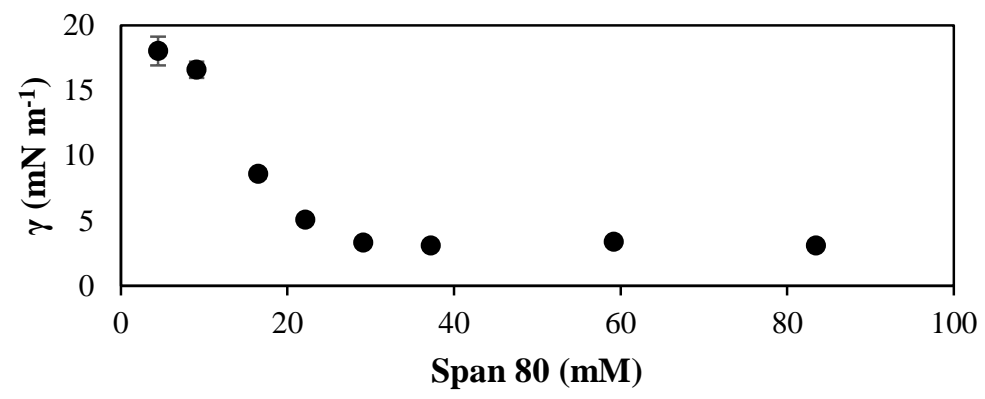

Figure 11. Estimated interfacial tension values for 13.5\% PVA solution injected in to kerosene for experiments performed at an injection rate of $1 \mathrm{~mL} \mathrm{~min}^{-1}$. Error bars are reported showing the standard deviation of the measurements.

It is possible to use this data to estimate the fraction of pores active in the process of membrane emulsification by equating the rate of drop growth from the active pores to the rate of adsorption of the surfactant. In order to achieve this, the surfactant diffusion coefficient must first be determined (see section 3.3).

\subsection{Surfactant adsorption dynamics}

Equation (6), from Ward and Tordai [35], relates the surfactant adsorption dynamics to the interfacial tension decline and the surfactant bulk concentration $\mathrm{C}_{0}$, the maximum loading of the interface with surfactant $\Gamma$, and the surfactant diffusion coefficient $\mathrm{D}$ :

$$
\gamma(t)-\gamma_{e q .}=\frac{R T \Gamma^{2}}{2 C_{0}} \sqrt{\frac{\pi}{D t}},
$$

$\Gamma$ can be determined by Gibb's isotherm, equation 6 , where $C_{S}$ is the subsurface concentration of surfactant in the surrounding phase solution [36]:

$$
\Gamma=-\frac{1}{R T}\left(\frac{d \gamma}{\operatorname{dln}\left(C_{S}\right)}\right)
$$

The concentration of surfactant achieves its maximum value at the CMC (and above) and is $1.5 \times 10^{-5} \mathrm{~mol} \mathrm{~m}^{-2}$. 
Figures 12 and 13, plot the dynamic interfacial tension data obtained from measurements using the DSA 100 (Kruss). The equilibrium interfacial tension $\left(\gamma_{\text {eq }}\right)$ was assumed to be the lowest value of the respective isotherm acquired. In Figure 12, the drop phase was distilled water and in Figure 13 there was an aqueous solution of 13.5\% (w/w) PVA. The inset shown in Figure 12 and 13 illustrates the surfactant diffusion coefficient $\left(\mathrm{s}^{-1}\right)$, using eq. 5, for different concentrations of $\operatorname{Span}^{\circledR}$ 80. The equilibrium interfacial tension is achieved much faster case when there is presence of a surfactant in the drop phase (PVA). Therefore, fewer data points were obtained and the absolute accuracy of the measurements is reduced. However, as can be seen in the insets included (Figure 12b and 13b), similar behaviour is observed which can be correlated by a power function. At first glimpse, data from Figure 13 looks scattered, but clearly the gradient of the slope of the curves reduces as the concentration of surfactant in the surrounding phase increases. In general, the diffusion coefficient is a measure of the rate of material transport, in this case, as the result of surfactant molecules movement towards the interface. Since mass transfer is dependent on diffusion (eq. 5), it is expected that oscillations in the continuous phase would influence surfactant adsorption rate. So, oscillations conditions were kept constant in order to exclude a potential variable during the drop formation experiments. 


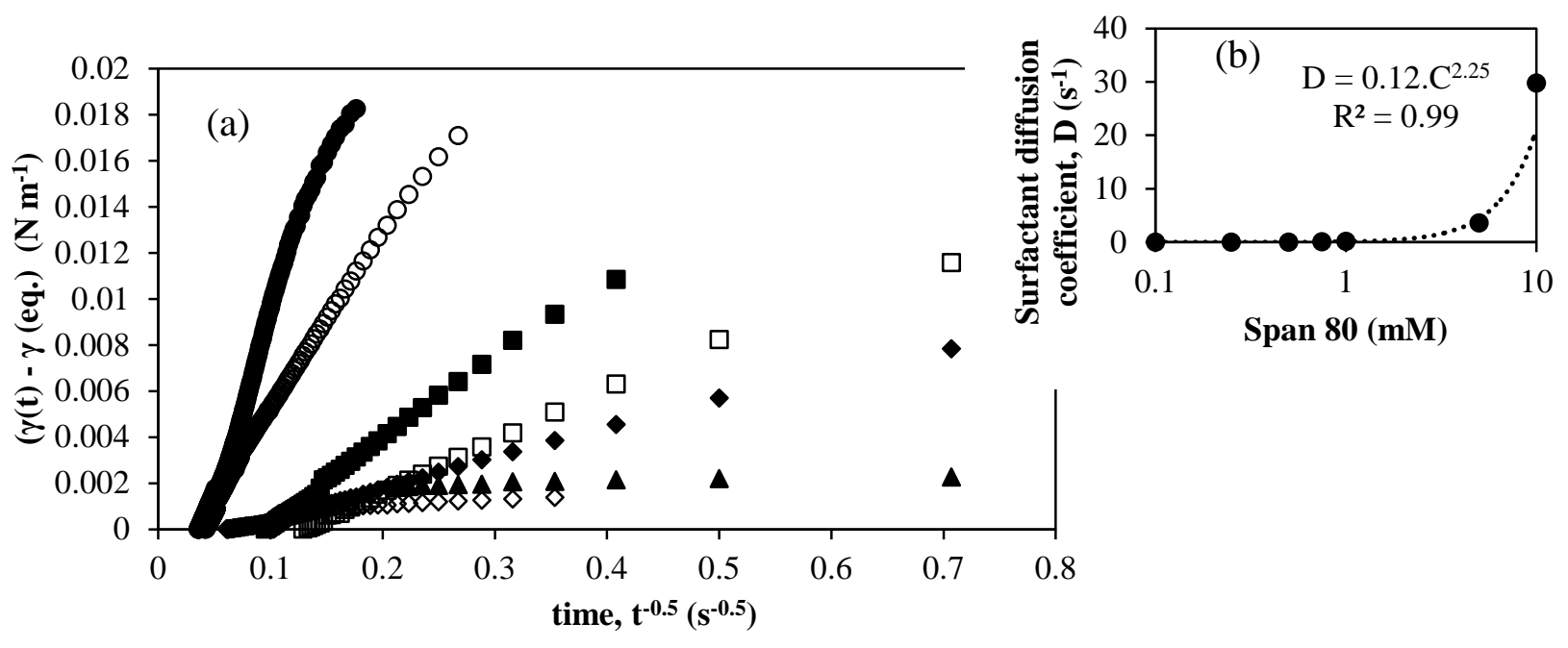

$\bullet 0.1 \mathrm{mM} \circ 0.25 \mathrm{mM} \square 0.5 \mathrm{mM} \square 0.75 \mathrm{mM} \bullet 1 \mathrm{mM} \diamond 5 \mathrm{mM} \Delta 10 \mathrm{mM}$

Figure 12. (a) Dynamic interfacial tension determined by pendant drop method of distilled water in kerosene that contained different concentrations of surfactant ( $\operatorname{Span}^{\circledR} 80$ ) dissolved: $0.1,0.25,0.5,0.75,1,5,10$ plotted according to eq. 5; with (b) inset showing surfactant diffusion coefficient for the different surfactant concentrations tested.

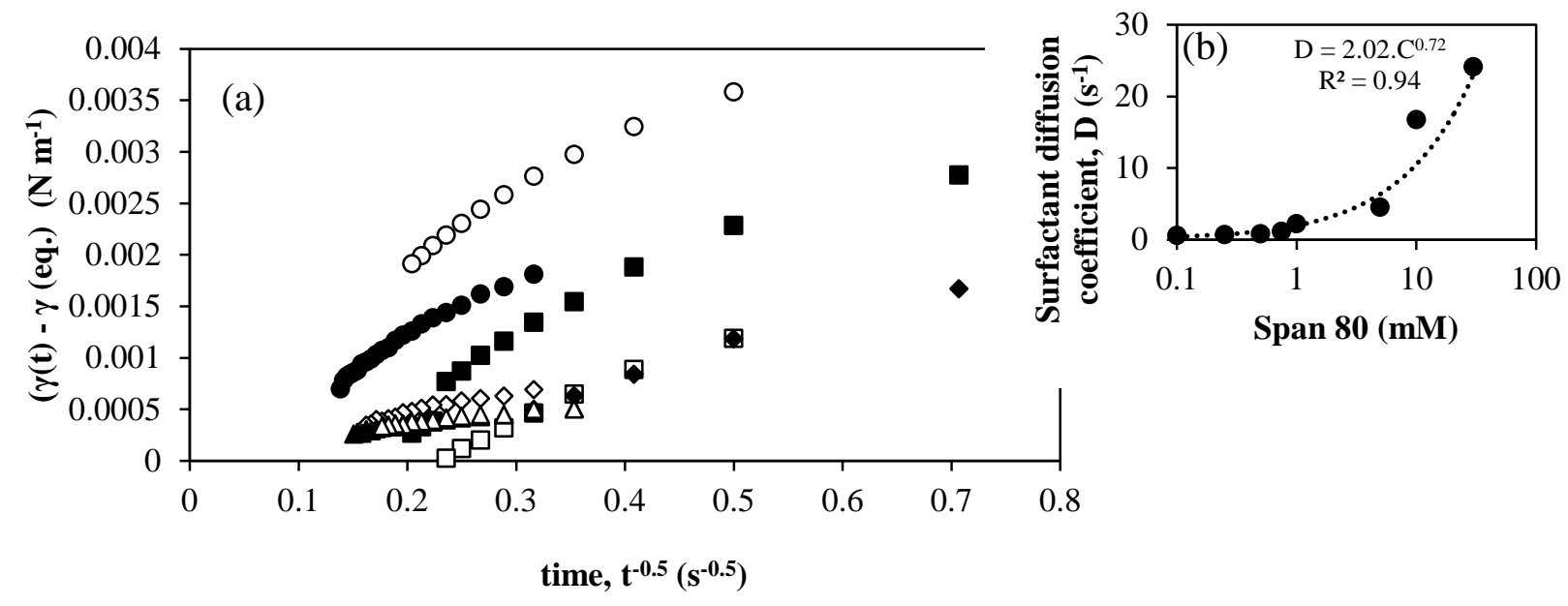

• $0.1 \mathrm{mM} \circ 0.25 \mathrm{mM} 0.5 \mathrm{mM} 00.75 \mathrm{mM} \bullet 1 \mathrm{mM} \diamond 5 \mathrm{mM} \Delta 10 \mathrm{mM} \Delta 30 \mathrm{mM}$

Figure 13. (a) Dynamic interfacial tension determined by pendant drop method of $13.5 \%$ wt. PVA in kerosene that contained different concentrations of surfactant (Span ${ }^{\circledR} 80$ ) dissolved: $0.1,0.25,0.5,0.75,1,5,10$ and $30 \mathrm{mM}$ plotted according to eq. 5; with (b) inset showing surfactant diffusion coefficient for the different surfactant concentrations tested. 
For a given drop size, it is possible to plot the drop frequency against active percentage of pores, using a material balance. Drop frequency $\left(\mathrm{d}_{\mathrm{f}}\right)$ is determined by:

$$
d_{f}=\frac{Q}{\frac{\pi}{6} n x^{3}}
$$

where $\mathrm{Q}$ is volumetric flow, $n$ is the number of pores and $x$ is the drop diameter. Looking at membrane design used (pore distance is greater 20 times than pore size), coalescence of neighbouring droplets emerging from the pores is very unlikely. Number of pores $(n)$ is determined by:

$$
n=\frac{\Phi A_{s}}{A_{p}}
$$

where $\Phi$ is the porosity of the membrane, $A_{s}$ is the surface (active) area and $A_{p}$ is the area of a single pore. Porosity of the membrane $(\Phi)$, with a triangular array (pores are spaced equidistantly) is determined by:

$$
\Phi=\frac{A_{p}}{2 A_{\Delta}} \times 100
$$

where $A_{\Delta}$ is the area of the triangular array.

For example, if fewer pores are active then they must produce drops at a higher frequency compared to a situation when a larger number of pores are active, in order to conform to the overall material balance of liquid being injected into the continuous phase, because volumetric flow is kept constant. This is illustrated in Figure 14, based on a drop size of 35.8 $\mu \mathrm{m}$, appropriate for the $29 \mathrm{mM}$ Span ${ }^{\circledR} 80$ concentration tests, and above. 


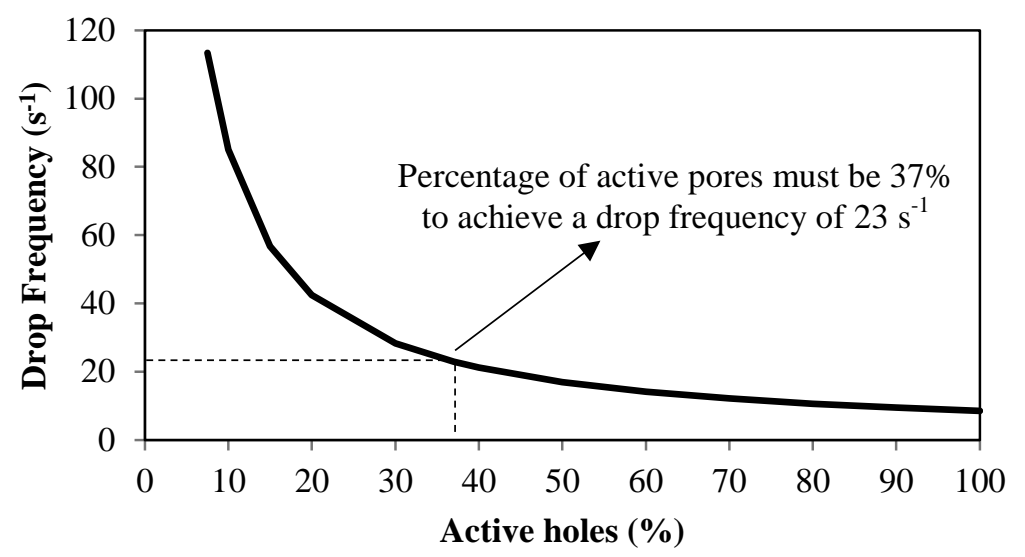

Figure 14. Drop frequency against fraction of active pores for a PVA drop size of $35.8 \mu \mathrm{m}$.

For the emulsification when a concentration of $29 \mathrm{mM}$ Span 80 was used (35.8 $\mu \mathrm{m}$ drop size) the surfactant diffusion coefficient was $23 \mathrm{~s}^{-1}$ (Figure 13b.). Assuming that surfactant diffusion coefficient is equal to the drop formation rate provides a percentage of active pores in the membrane to be $37 \%$ (see Figure 14). This value is consistent with the expected value for membrane emulsification when using this type of regular, and non-tortuous, type of pore channel membrane structure [3, 9-11]. It is the first time that this approach to analysing the number of pores active in the process of membrane emulsification has been determined, rather than simply providing a range of values that may be relevant [24], and it could be used to investigate methods to improve the pore utilisation to enhance productivity.

When the number of active pores is known, then pore velocity can also be calculated. Therefore, Capillary number and Weber number may also be estimated and better determination of whether working conditions are within the dripping or jetting regimes. 


\section{Conclusions}

A straightforward technique for hydrophization of a metal surface, based on chemisorption of a fluoroalkylsilane, for the purpose of membrane emulsification is described. It requires a certain degree of surface oxidation, which is shown to occur naturally within a matter of one hour after cleaning, and the nature of the chemical cleaning did not appear to be important. The resulting contact angle of water on the metal surface in air was $110 \pm 8^{\circ}$ degrees, and this increased to $150 \pm 5^{\circ}$ degrees when the water droplet was surrounded by kerosene. Using the hydrophobized metal (nickel) membrane for the production of water-in-oil emulsions, a PVA solution was injected in to kerosene containing $\operatorname{Span}^{\circledR}$ 80. As a result, drops with a CV of about $20 \%$ were produced. A range of $\operatorname{Span}^{\circledR} 80$ concentrations were investigated and above a concentration of $29 \mathrm{mM}$ (i.e. 57 times the CMC value) there was sufficient surfactant present such that the drop size did not change with increasing surfactant concentration, it remained constant around $36 \mu \mathrm{m}$. However, when surfactant concentrations were less than 29 $\mathrm{mM}$, the expansion rate of the drops emerging from the $10 \mu \mathrm{m}$ pore-size membrane was greater than the adsorption rate of the drop stabilising surfactant. This led to a situation whereby there was a lower concentration of surfactant at the water-oil interface than would occur at equilibrium, hence the interfacial tension was greater than the equilibrium value. It was possible to deduce the dynamic interfacial tension from the drop size formed. Under these conditions, larger drops were observed when operating at the equilibrium surfactant concentration at the interface occurred, and a previously published force-momentum balance was used to provide a deduced dynamic interfacial tension value using these measured drop sizes. The dynamic interfacial tension values were between the equilibrium interfacial tension of $3 \pm 0.8 \mathrm{mN} \mathrm{m}^{-1}$ and the interfacial tension between water and kerosene with no surfactant 
present, $38 \pm 1.9 \mathrm{mN} \mathrm{m}^{-1}$, i.e., when the interface is free of surface active agents, either PVA or $\operatorname{Span}^{\circledR} 80$.

Data from a parallel study of surfactant adsorption provided a surface adsorption rate, which when combined with the droplet formation rate at the membrane provided a means to estimate the percentage of active pores within the membrane. The membrane used in the study had a very regular matrix of very uniform pores, rather than the usual tortuous pore channel depth filter commonly used for membrane emulsification. However, even with this regular pore geometry the deduced percentage of active pores was only about $37 \%$, when operating with $29 \mathrm{mM}$ surfactant concentration and above. This suggests that there is scope for improving productivity of this membrane system, if the percentage pore utilisation could be increased. The technique described for determining the active pore utilisation of a membrane, used for membrane emulsification, can be applied to different types of membranes.

\section{Acknowledgements}

P. Silva kindly acknowledges O. Arjmandi-Tash and Dr. G. Ahmed for the scientific discussions and their insight. This work was supported by Micropore Technologies Ltd and prepared in the framework of the Marie Curie Initial Training Network "Complex Wetting Phenomena” (CoWet), grant no. 607861. 


\section{List of Figures:}

Figure 1. Representation of the ideal chemical structure of the fluoroalkylsilane/metallic interphase region $\mathrm{R}=\mathrm{CH}_{2} \mathrm{CH}_{2}\left(\mathrm{CF}_{2}\right)_{7} \mathrm{CF}_{3}$ (adapted from [25]).

Figure 2. Representation of the vertical oscillating membrane emulsification device used with an inset showing the regular pore pattern of the membrane (triangular array) and the shape of the tubular membrane used. Adapted from [24]. 9

Figure 3. Illustration of the home-made sessile droplet experimental equipment.

Figure 4. Apparent contact angle $\left(\Theta_{\mathrm{app}}\right)$ monitoring of sessile water drops on stainless steel sheets that were exposed to 4M NaOH (“alkali”), $2 \%$ (wt) citric acid or $10 \%$ (w/w) $\mathrm{HCl}$ over a variable drying period. 14

Figure 5. Apparent contact angle $\left(\Theta_{\mathrm{app}}\right)$ measurements of sessile water drops on stainless steel sheets that were "FAS treated" using different concentrations of $1 \mathrm{H}, 1 \mathrm{H}, 2 \mathrm{H}, 2 \mathrm{H}-$ Perfluorododecyltriethosysilane $(0.0001 \mathrm{M}, 0.001 \mathrm{M}, 0.01 \mathrm{M}$ and $0.1 \mathrm{M})$ in undecane for various periods of time (1-7 days) at room temperature. As control, the presence of FAS chemical was avoided, exposing the surface only to undecane. The stainless steel used in the set named “0.01M No HCL” was not cleaned using $\mathrm{HCl}$, all the others were. .15

Figure 6. Apparent contact angle $\left(\Theta_{\mathrm{app}}\right)$ measurements of sessile water drops on stainless steel sheets that were "FAS treated" using a concentration of $0.01 \mathrm{M}$ of $1 \mathrm{H}, 1 \mathrm{H}, 2 \mathrm{H}, 2 \mathrm{H}-$ Perfluorododecyltriethosysilane in undecane for 4 hours and 24 hours at $45^{\circ} \mathrm{C}$. .16 Figure 7. Image of a sessile water drop on a hydrophobic stainless steel (FAS treated) surface: (a) in air and (b) in kerosene, illustrating the interfacial tensions involved. .16 Figure 8. w/o emulsions produced using (a-PTFE) a new PTFE coated membrane, (b-PTFE) PTFE coated membrane after 4 uses, (c- FAS) a new FAS treated membrane and (d- FAS) a FAS treated membranes after 4 uses. 
Figure 9. Median droplet diameters $(\bullet)$ and coefficient variation $(\mathrm{CV})$ values $(\mathrm{O})$ of PVA droplets in kerosene as a function of concentration of $\operatorname{Span}^{\circledR} 80$ for a (constant) flow of $1 \mathrm{~mL}$ $\min ^{-1}$ during membrane emulsification of a FAS treated metal (nickel) membrane. Error bars are reported showing the standard deviation of the measurements. 20

Figure 10. Droplets formed during injection of $13.5 \%$ PVA solution at $1 \mathrm{~mL} \mathrm{~min}^{-1}$ in to kerosene with $40 \mathrm{mM}$ Span ${ }^{\circledR} 80$ surfactant concentration using a surface shear of $7.3 \mathrm{~Pa}$......20 Figure 11. Estimated interfacial tension values for $13.5 \%$ PVA solution injected in to kerosene for experiments performed at an injection rate of $1 \mathrm{~mL} \mathrm{~min}{ }^{-1}$. Error bars are reported showing the standard deviation of the measurements. .22

Figure 12. (a) Dynamic interfacial tension determined by pendant drop method of distilled water in kerosene that contained different concentrations of surfactant ( $\left.\operatorname{Span}^{\circledR} 80\right)$ dissolved: $0.1,0.25,0.5,0.75,1,5,10$ plotted according to eq. 5; with (b) inset showing surfactant diffusion coefficient for the different surfactant concentrations tested. .24

Figure 13. (a) Dynamic interfacial tension determined by pendant drop method of $13.5 \%$ wt. PVA in kerosene that contained different concentrations of surfactant (Span $\left.{ }^{\circledR} 80\right)$ dissolved: $0.1,0.25,0.5,0.75,1,5,10$ and $30 \mathrm{mM}$ plotted according to eq. 5; with (b) inset showing surfactant diffusion coefficient for the different surfactant concentrations tested. .24 Figure 14. Drop frequency against fraction of active pores for a PVA drop size of $35.8 \mu \mathrm{m} .26$ 


\section{References}

1. Joscelyne, S.M. and G. Trägårdh, Food emulsions using membrane emulsification: conditions for producing small droplets. Journal of Food Engineering, 1999. 39(1): p. 59-64.

2. Peng, S.J. and R.A. Williams, Controlled production of emulsions using a crossflow membrane part I: Droplet formation from a single pore. Chemical Engineering Research \& Design, 1998. 76(A8): p. 894-901.

3. Schroder, V., O. Behrend, and H. Schubert, Effect of dynamic interfacial tension on the emulsification process using microporous, ceramic membranes. Journal of Colloid and Interface Science, 1998. 202(2): p. 334-340.

4. Nakashima, T., M. Shimizu, and M. Kukizaki, Membrane Emulsification by Microporous Glass. Key Engineering Materials, 1991. 61-62: p. 513-516.

5. Omi, S., Preparation of monodisperse microspheres using the Shirasu porous glass emulsification technique. Colloids and Surfaces A: Physicochemical and Engineering Aspects, 1996. 109: p. 97-107.

6. Vladisavljević, G.T., Structured microparticles with tailored properties produced by membrane emulsification. Advances in Colloid and Interface Science, 2015. 225: p. 53-87.

7. Vladisavljević, G.T., M. Shimizu, and T. Nakashima, Permeability of hydrophilic and hydrophobic Shirasu-porous-glass (SPG) membranes to pure liquids and its microstructure. Journal of Membrane Science, 2005. 250(1-2): p. 69-77.

8. Silva, P.S., M.M. Dragosavac, G.T. Vladisavljević, H.C.H. Bandulasena, R.G. Holdich, M. Stillwell, and B. Williams, Azimuthally oscillating membrane 
emulsification for controlled droplet production. AIChE Journal, 2015. 61(11): p. 3607-3615.

9. Geerken, M.J., R.G.H. Lammertink, and M. Wessling, Interfacial aspects of water drop formation at micro-engineered orifices. Journal of Colloid and Interface Science, 2007. 312(2): p. 460-469.

10. Sugiura, S., M. Nakajima, J. Tong, H. Nabetani, and M. Seki, Preparation of Monodispersed Solid Lipid Microspheres Using a Microchannel Emulsification Technique. Journal of Colloid and Interface Science, 2000. 227(1): p. 95-103.

11. Vladisavljevic, G.T. and H. Schubert, Preparation and analysis of oil-in-water emulsions with a narrow droplet size distribution using Shirasu-porous-glass (SPG) membranes. Desalination, 2002. 144(1): p. 167-172.

12. Geerken, M.J., R.G.H. Lammertink, and M. Wessling, Tailoring surface properties for controlling droplet formation at microsieve membranes. Colloids and Surfaces A: Physicochemical and Engineering Aspects, 2007. 292(2-3): p. 224-235.

13. Morelli, S., R.G. Holdich, and M.M. Dragosavac, Chitosan and Poly (Vinyl Alcohol) microparticles produced by membrane emulsification for encapsulation and $\mathrm{pH}$ controlled release. Chemical Engineering Journal, 2016. 288: p. 451-460.

14. Holdich, R.G., M.M. Dragosavac, G.T. Vladisavljevic, and E. Piacentini, Continuous Membrane Emulsification with Pulsed (Oscillatory) Flow. Industrial \& Engineering Chemistry Research, 2013. 52(1): p. 507-515.

15. Liggieri, L. and R. Miller, Relaxation of surfactants adsorption layers at liquid interfaces. Current Opinion in Colloid \& Interface Science, 2010. 15(4): p. 256-263.

16. Truszkowska, D., F. Henrich, J. Schultze, K. Koynov, H.J. Räder, H.J. Butt, and G.K. Auernhammer, Forced dewetting dynamics of high molecular weight surfactant solutions. Colloids and Surfaces A: Physicochemical and Engineering Aspects, 2016. 
17. van der Graaf, S., C.G.P.H. Schroën, R.G.M. van der Sman, and R.M. Boom, Influence of dynamic interfacial tension on droplet formation during membrane emulsification. Journal of Colloid and Interface Science, 2004. 277(2): p. 456-463.

18. Abrahamse, A.J., A. van der Padt, and R.M. Boom, Influence of membrane morphology on pore activation in membrane emulsification. Journal of Membrane Science, 2003. 217(1-2): p. 141-150.

19. Abrahamse, A.J., R. van Lierop, R.G.M. van der Sman, A. van der Padt, and R.M. Boom, Analysis of droplet formation and interactions during cross-flow membrane emulsification. Journal of Membrane Science, 2002. 204(1-2): p. 125-137.

20. Gasparini, G., S.R. Kosvintsev, M.T. Stillwell, and R.G. Holdich, Preparation and characterization of PLGA particles for subcutaneous controlled drug release by membrane emulsification. Colloids and Surfaces B: Biointerfaces, 2008. 61(2): p. 199-207.

21. Kemala, T., E. Budianto, and B. Soegiyono, Preparation and characterization of microspheres based on blend of poly(lactic acid) and poly(e-caprolactone) with poly(vinyl alcohol) as emulsifier. Arabian Journal of Chemistry, 2012. 5(1): p. 103108.

22. Alroaithi, M. and S. Sajjadi, Uniform polymer beads by membrane emulsificationassisted suspension polymerisation. RSC Advances, 2016. 6(83): p. 79745-79754.

23. Stillwell, M.T., R.G. Holdich, S.R. Kosvintsev, G. Gasparini, and I.W. Cumming, Stirred cell membrane emulsification and factors influencing dispersion drop size and uniformity. Industrial \& Engineering Chemistry Research, 2007. 46(3): p. 965-972.

24. Holdich, R.G., M.M. Dragosavac, G.T. Vladisavljevic, and S.R. Kosvintsev, Membrane Emulsification with Oscillating and Stationary Membranes. Industrial \& Engineering Chemistry Research, 2010. 49(8): p. 3810-3817. 
25. Beentjes, P.C.J., Durability of Polymer Coated Steel in Diluted Acetic Acid Environment, 2004, Technishce Universiteit Delft: Delft, Netherlands.

26. Chao, T.C., O. Arjmandi-Tash, D.B. Das, and V.M. Starov, Simultaneous spreading and imbibition of blood droplets over porous substrates in the case of partial wetting. Colloids and Surfaces A: Physicochemical and Engineering Aspects.

27. Feng, L., S. Li, Y. Li, H. Li, L. Zhang, J. Zhai, Y. Song, B. Liu, L. Jiang, and D. Zhu, Super-Hydrophobic Surfaces: From Natural to Artificial. Advanced Materials, 2002. 14(24): p. 1857-1860.

28. Deng, X., L. Mammen, Y. Zhao, P. Lellig, K. Müllen, C. Li, H.-J. Butt, and D. Vollmer, Transparent, Thermally Stable and Mechanically Robust Superhydrophobic Surfaces Made from Porous Silica Capsules. Advanced Materials, 2011. 23(26): p. 2962-2965.

29. Javadi, A., N. Mucic, M. Karbaschi, J.Y. Won, M. Lotfi, A. Dan, V. Ulaganathan, G. Gochev, A.V. Makievski, V.I. Kovalchuk, N.M. Kovalchuk, J. Krägel, and R. Miller, Characterization methods for liquid interfacial layers. The European Physical Journal Special Topics, 2013. 222(1): p. 7-29.

30. Gan, D., W. Cao, and Z. Wang, Synthesis and surface properties of a fluorinated polyether. Journal of Fluorine Chemistry, 2002. 116(1): p. 59-63.

31. Inoue, Y., Y. Yoshimura, Y. Ikeda, and A. Kohno, Ultra-hydrophobic fluorine polymer by Ar-ion bombardment. Colloids and Surfaces B: Biointerfaces, 2000. 19(3): p. 257-261.

32. Caro, J.C., U. Lappan, F. Simon, D. Pleul, and K. Lunkwitz, On the low-pressure plasma treatment of PTFE (polytetrafluoroethylene) with SO2 as process gas. European Polymer Journal, 1999. 35(6): p. 1149-1152. 
33. Schroën, K., M. Ferrando, S. de Lamo-Castellví, S. Sahin, and C. Güell, Linking Findings in Microfluidics to Membrane Emulsification Process Design: The Importance of Wettability and Component Interactions with Interfaces. Membranes, 2016. 6(2): p. 26.

34. Morelli, S., R.G. Holdich, and M.M. Dragosavac, Microparticles for cell encapsulation and colonic delivery produced by membrane emulsification. Journal of Membrane Science, 2017. 524: p. 377-388.

35. Joos, P. and E. Rillaerts, Theory on the determination of the dynamic surface tension with the drop volume and maximum bubble pressure methods. Journal of Colloid and Interface Science, 1981. 79(1): p. 96-100.

36. Rayner, M., G. Trägårdh, and C. Trägårdh, The impact of mass transfer and interfacial expansion rate on droplet size in membrane emulsification processes. Colloids and Surfaces A: Physicochemical and Engineering Aspects, 2005. 266(1-3): p. 1-17. 